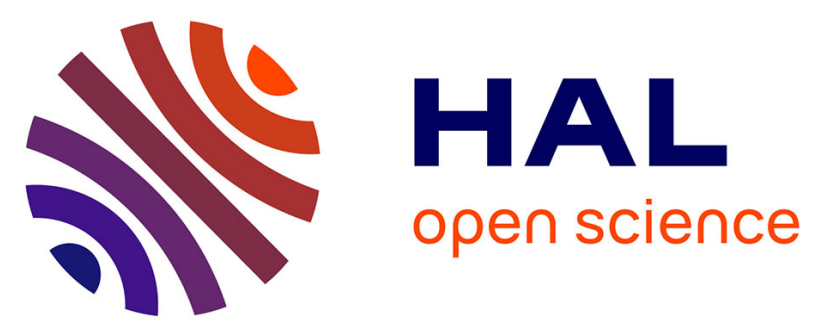

\title{
Shrub-oak seedling spatial associations change in response to the functional composition of neighbouring shrubs in coastal dune forest communities
}

Hassan Muhamed, Emanuele Lingua, Jean-Paul Maalouf, Richard Michalet

\section{- To cite this version:}

Hassan Muhamed, Emanuele Lingua, Jean-Paul Maalouf, Richard Michalet. Shrub-oak seedling spatial associations change in response to the functional composition of neighbouring shrubs in coastal dune forest communities. Annals of Forest Science, 2015, 72 (2), pp.231-241. 10.1007/s13595-0140419-8 . hal-01284168

\author{
HAL Id: hal-01284168 \\ https://hal.science/hal-01284168
}

Submitted on 7 Mar 2016

HAL is a multi-disciplinary open access archive for the deposit and dissemination of scientific research documents, whether they are published or not. The documents may come from teaching and research institutions in France or abroad, or from public or private research centers.
L'archive ouverte pluridisciplinaire HAL, est destinée au dépôt et à la diffusion de documents scientifiques de niveau recherche, publiés ou non, émanant des établissements d'enseignement et de recherche français ou étrangers, des laboratoires publics ou privés.

$$
\text { Copyright }
$$




\title{
Shrub-oak seedling spatial associations change in response to the functional composition of neighbouring shrubs in coastal dune forest communities
}

\author{
Hassan Muhamed • Emanuele Lingua • \\ Jean-Paul Maalouf $•$ Richard Michalet
}

Received: 15 January 2014 / Accepted: 1 September 2014 /Published online: 25 September 2014

(C) INRA and Springer-Verlag France 2014

\begin{abstract}
- Context The abundance and distribution of tree regeneration is driven by several processes acting at both the seedling establishment and survival stages. Plant- plant interactions highly contribute to regeneration dynamics through seed dispersal and competition or facilitation processes.

- Aims The aim of the present study was to assess the relative importance of different functional groups of shrubs for the early establishment of oak seedlings in the coastal forest communities of south-western France.

- Material and methods We applied spatial and non-spatial analysis methods in eleven $315-\mathrm{m}^{2}$ regeneration plots. Within
\end{abstract}

\section{Handling Editor: Laurent Bergès}

Contribution of the co-authors Jean-Paul Maalouf: supporting in data analysis and scientific discussion.

Emanuele Lingua: supporting in data analysis and scientific discussion. Richard Michalet: designing and supervising the experiment.

Electronic supplementary material The online version of this article (doi:10.1007/s13595-014-0419-8) contains supplementary material, which is available to authorized users.

H. Muhamed $(\bowtie) \cdot$ J.-P. Maalouf

University of Bordeaux, U.M.R. INRA 1202 BIOGECO,

Avenue des Facultés, 33405 Talence cedex, France

e-mail: hassan.muhamed@uod.ac

J.-P. Maalouf

e-mail: jeanpaul.maalouf@gmail.com

R. Michalet

University of Bordeaux, U.M.R. CNRS 5805 EPOC, Avenue des Facultés, 33405 Talence cedex, France

e-mail: r.michalet@ecologie.u-bordeaux1.fr

E. Lingua

Department TESAF, University of Padova,

Viale dell'Università, 16, I-35020 Legnaro, PD, Italy

e-mail: emanuele.lingua@unipd.it each plot, oak seedlings (height $<25 \mathrm{~cm}$ ) and shrubs (height $>50 \mathrm{~cm}$ and $\mathrm{DBH}<4 \mathrm{~cm}$ ) were mapped to $\pm 1 \mathrm{~cm}$. The spatial distribution patterns of the oak seedlings (Quercus robur, Quercus suber and Quercus ilex) were analysed for each species while the association patterns were detected between the seedlings of the three oaks and four functional groups of shrubs (Fagaceae, Ericaceae, Fabaceae and spiny shrubs) known to have contrasting effects on other species.

- Results Oak seedling species were very often spatially aggregated at short distances $(<1 \mathrm{~m})$. Oak seedlings were also positively associated with shrubs of the same species within the Fagaceae group, whereas we detected negative associations with Ericaceae and no dominant significant pattern for Fabaceae and spiny shrubs.

- Conclusion The aggregated distribution of seedlings of the three oak species was due to short-distance seed dispersal, which also explained their positive spatial associations with Fagaceae shrubs. Thus, in order to enhance oak recruitment in these ecosystems, forest managers should focus on the control of Ericaceae shrubs, while preserving Fagaceae shrubs.

Keywords Ericaceae $\cdot$ Intraspecific aggregation - Coastal dunes $\cdot$ Oak seedling $\cdot$ Spatial association $\cdot$ Tree regeneration

\section{Introduction}

Natural regeneration represents a highly complex process in forest dynamics since many mechanisms are involved (Paluch 2005). Seedling establishment and survival depend on seed (i.e. dispersal strategies), microsite (i.e. spatial heterogeneity) availability and local neighbouring interactions which may separately or jointly control the regeneration process (Hille Ris Lambers and Clark 2003).

During the early phase of the regeneration cycle, tree seedlings are influenced by the presence and abundance of 
overstory canopy. In particular, shrubs are recognized as important tree regeneration niches, because their canopies may have facilitative effects on the establishment of different tree species (Callaway 1995; Rodriguez-Garcia et al. 2011; Muhamed et al. 2013b). However, only some shrub species have a positive effect on tree regeneration through amelioration of climatic and edaphic conditions below their canopies (i.e. interspecific facilitation or the "nurse plant effect", Callaway 1995), while others have effects varying between competitive to neutral. For example, GómezAparicio et al. (2004) have shown the positive influence of Fabaceae shrubs and the negative influence of rockroses (Cistaceae) in a meta-analysis conducted on restoration experiments in south-east Spain depending on the elevation and the slope of the study site. The positive effects of Fabaceae have been observed by several other authors, in particular for Retama sphaerocarpa species in the Mediterranean region (Cuesta et al. 2010). In contrast, Cistaceae and Ericaceae species have often negative influences, likely because of their allelopathic effects (Gonzalez-Martinez and Bravo 2001), whereas spiny shrubs are known to provide protection against herbivory (Callaway 1995). "Fertile islands" formed by shrubs are frequently more favourable to other species recruits than to their own offspring, although intraspecific facilitation has been observed between individuals of different-sized cohorts with large individuals protecting small seedlings of the same species (Fajardo and McIntire 2011).

In forest ecosystems, the initial horizontal distribution pattern of seedlings and their vertical spatial associations with the overstory canopy are considered a fundamental step to be identified in natural regeneration studies. These two-dimensional spatial patterns of individual trees in a forest drive long-term forest community dynamics by influencing competition levels, growth rates and understory development (Goreaud et al. 1999). Fine-scale spatial patterns of woody plant regeneration have been studied to uncover causal mechanisms that facilitate species coexistence (Wiegand and Moloney 2004). Spatial point pattern analysis is one of the most common approaches used to infer positive and negative plant-plant interactions and had been used in various ecosystems and for many species (Wiegand and Moloney 2004). Mainly, observed patterns at small spatial scale have been related to either positive or negative plant interactions. For example, regular plant spatial patterns are often referred as a sign of intense competition between plants for limited resources. In contrast, aggregated patterns (especially interspecific) are interpreted as evidence of positive plant interactions, short-distance seed dispersion as gravity-dispersed or seed cached by birds and small rodents; the random patterns suggest no strong, direct influence of any process in shaping spatial relationships, although they could be transitions phases between aggregated and regular patterns (Rayburn et al. 2011).

In coastal dune communities, the major limiting factors for plant regeneration are high light and summer temperatures and the scarcity of available water and nutrients (Maun 1998). Microenvironmental changes provided by nurse plants are important for seedling establishment particularly in seasonally dry ecosystems with a high seedling mortality rate during this critical stage. For example, in Mediterranean, sub-Mediterranean and Atlantic coastal sand dunes, shrubs frequently improve seedling regeneration (Shumway 2000; Cushman et al. 2010). In the Aquitaine region (south-western France), the coastal dune forest communities are mainly composed of three oak species within a spatially heterogeneous matrix of shrubs.

The main purpose of this study was to evaluate spatial associations between oak seedlings and four functional groups of shrubs (Fagaceae, spiny, Fabaceae and Ericaceae) known to have contrasting effects on other species. We used both spatial and non-spatial methods to assess if oak seedlings were spatially associated with specific functional groups of shrubs, independently on climate and canopy conditions. Additionally, we analysed the spatial patterns of oak seedlings separately for each species. Together, these different approaches allowed us to assess both interspecific and intraspecific biotic drivers of oak regeneration dynamics in the coastal dune forests. In a previous study conducted in the same ecosystem, Muhamed et al. (2013a) examined the magnitude of the net effect of shrubs (pooled in only one group) on the early establishment of each of the three oak seedling species (Quercus robur L., Q. suber L. and $Q$. ilex L) and showed that the three oak species do not differ significantly in their association patterns with shrubs, which were rather dependent on climate and canopy conditions. By assessing the role of the different functional groups of shrub species on the natural establishment of oak seedlings, we would like to provide useful information to be implemented in management practices targeting oak regeneration enhancement.

Based on previous work, we expected that (i) all three species of oak seedlings would be aggregated at fine scales and (ii) oak seedlings would display the following:

- Positive spatial associations with Fabaceae shrubs due to nitrogen fixation and scarce nutrient in coastal dune soils

- Positive associations with spiny shrubs as a result of protection against herbivores

- Positive associations with Fagaceae as a result of both dispersal and microclimate improvement

- Negative associations with Ericaceae, because of their allelopathic effects 


\section{Materials and methods}

\subsection{Study site and target species}

The study took place in the coastal sand dune forests of the Aquitaine Region (south-western France). In Aquitaine, coastal dunes occur within an approximately $240 \mathrm{~km}$ long sand strip expanding from the Gironde estuary in the north $\left(45^{\circ} 32^{\prime}\right.$ $\left.\mathrm{N}, 1^{\circ} 05^{\prime} \mathrm{W}\right)$ to the mouth of the Adour river in the south $\left(43^{\circ}\right.$ $\left.41^{\prime} \mathrm{N}, 1^{\circ} 25^{\prime} \mathrm{W}\right)$ at the vicinity of the Pyrenees mountain range.

All along the coast, oak forest communities occur in the inland fossil dunes at approximately $1-10-\mathrm{km}$ distance from the ocean. The study area is bioclimatically classified as temperate oceanic, with temperatures increasing from the north to the south and an average of $13.5^{\circ} \mathrm{C}$ (12.8 to $14.10{ }^{\circ} \mathrm{C}$, respectively) while the rainiest period of the year occurs during winter. There is an increase in mean annual precipitation with decreasing distance from the Pyrenees mountain range southwards $(750 \mathrm{~mm}$ in the north to $1,300 \mathrm{~mm}$ in the south) (Sardin 2009). The soil is very homogeneous all along the coast and is a young podzol soil with a pure coarse sandy texture (Forey et al. 2008).

In eastern exposure where the oldest oak forests with a natural regeneration are still present, five latitudinal positions were selected from south to north. Furthermore, we delimited an additional site with a west-facing slope in the central part of the latitudinal gradient, where the climate is intermediate to assess the effect of exposure. At each latitudinal and exposure position, two plots within 1-km distance were selected, one in a closed canopy forest and one in a gap to also assess canopy closure variations. However, in the northernmost site (Soulac), we only established one forest plot since we could not find a suitable gap for the study (Table 1). All forest plots were located in mature forests with virtually not less than $75 \%$ canopy closure by mixed oak tree overstory, and all open plots were gaps created recently (3-5 years) by opening overstory canopy through seed tree cutting. Each gap had a minimum size of 0.5 ha in order to have microclimatic conditions not influenced by the surrounding adult trees, as shown by Muhamed et al. (2013a). Under the two canopy conditions in the middle part of a moderate slope (steepness varying between 15 and $25^{\circ}$ ), we delimited a uniform and homogeneous permanent $315-\mathrm{m}^{2}$ plot. All sites are subjected to natural herbivory by deers.

We chose to study the regeneration of the three dominant oak species in the region, the evergreen sclerophyllous $Q$. ilex and $Q$. suber and the deciduous $Q$. robur. $Q$. ilex is the most drought-tolerant species and occurred mostly in the drier part of the gradient, in the north. Q. suber, which is more cold- and drought-sensitive than $Q$. ilex, mainly occurs in the wettest and mildest part of the gradient in the south (Michalet 1991; David et al. 2007). Q. robur occurs all along the gradient but was more abundant in the central part of the gradient where the two other species were rare (Sardin 2009). Although the three species have different stress tolerance strategies, they are all highly or intermediately shade-tolerant since they are rather late-successional species as most Fagaceae species (Rameau et al. 1993). This likely explains why Muhamed et al. (2013a) did not find any difference in spatial associations with shrubs among those three oak species.

\subsection{Data collection}

In September 2009, we mapped the woody vegetation within the eleven $315-\mathrm{m}^{2}$ rectangular plots by dividing each plot into $359-\mathrm{m}^{2}$ quadrats. The Cartesian coordinates of each plant were recorded by using a measuring tape to estimate the distance $( \pm 1 \mathrm{~cm})$ of the main stem of each individual to reference axes with origins $(x, y=0.0)$ located in the lower right corner of the plot. We assigned each woody plant to one of three size categories: (i) seedlings (height $<25 \mathrm{~cm}$ ), (ii) saplings $(25<$ height $<50 \mathrm{~cm})$ and (iii) shrubs (height $>50 \mathrm{~cm}$ and $\mathrm{DBH}<4 \mathrm{~cm}$ ). For shrubs, we also recorded the four coordinate points defining the crown (approximated to an ellipse). Because of small sample size, we excluded adult oak trees from the analysis, and oak seedlings and saplings were pooled into one category, thereafter called seedlings. In order to assess the contrasting effects of different functional groups of shrubs on oak seedling recruitment, we pooled the different shrub species into four functional groups based on their morphological traits and, thus, their likeable effects on other species: (i) Fagaceae (Q. robur, Q. suber, Q. ilex), (ii) spiny shrubs (Ilex aquifolium, Ruscus aculeatus), Fabaceae (Ulex europaeus, Cytisus scoparius) and (iv) Ericaceae (Arbutus unedo, Erica cinerea, Calluna vulgaris). Spiny shrubs are known to have protection effects against herbivores, Fabaceae for their ability to fix nitrogen and Ericaceae for their allelopathic effects (Callaway 1995; Gonzalez-Martinez and Bravo 2001; Gómez-Aparicio et al. 2004). Finally, we pooled the three oak shrubs within a fourth group "Fagaceae" because we assumed that they do not have specific effects in contrast to the three other groups and might be sensitive to intraspecific associations with the target seedlings.

\subsection{Data analysis}

In this study, we analysed the spatial distribution patterns, separately for the seedlings of each of the three oak species, using univariate pair correlation function (Wiegand and Moloney 2004). In a previous study, the same ecosystem showed no significant variation in spatial association patterns with pooled shrub species among the three oak species (Q. robur, Q. ilex and Q. suber) (Muhamed et al. 2013a). In addition, since the three oak species do not occur across all plots (i.e. $Q$. ilex was only presented in northern plots while 
Table 1 Main characteristics of the 11 study plots

\begin{tabular}{llllll}
\hline Study plot & Canopy treatment & Coordinates & Aspect & Oak species seedling & Main shrub species \\
\hline Soulac (So.) & Forest & $45^{\circ} 32^{\prime} \mathrm{N}, 1^{\circ} 05^{\prime} \mathrm{W}$ & $\mathrm{E}$ & Q. robur, Q. ilex & Arbutus unedo, Ruscus aculeatus, Q. ilex \\
Hourtin (Ho.) & Forest & $45^{\circ} 11^{\prime} \mathrm{N}, 1^{\circ} 03^{\prime} \mathrm{W}$ & $\mathrm{E}$ & Q. robur, Q. ilex & Q. ilex \\
& Gap & $44^{\circ} 09^{\prime} \mathrm{N}, 1^{\circ} 10^{\prime} \mathrm{W}$ & $\mathrm{E}$ & Q. robur, Q. ilex & Cytisus scoparius, Q. ilex, Q. robur \\
Biscarrosse 1 (Bisc. 1) & Forest & $44^{\circ} 26^{\prime} \mathrm{N}, 1^{\circ} 13^{\prime} \mathrm{W}$ & $\mathrm{E}$ & Q. robur & Ilex aquifolium, A. unedo, Q. robur \\
& Gap & $44^{\circ} 01^{\prime} \mathrm{N}, 1^{\circ} 12^{\prime} \mathrm{W}$ & $\mathrm{E}$ & Q. robur & A. unedo, Q. robur \\
Biscarrosse 2 (Bisc. 2) & Forest & $44^{\circ} 27^{\prime} \mathrm{N}, 1^{\circ} 13^{\prime} \mathrm{W}$ & $\mathrm{W}$ & Q. robur & C. scoparius, A. unedo \\
& Gap & $44^{\circ} 26^{\prime} \mathrm{N}, 1^{\circ} 12^{\prime} \mathrm{W}$ & $\mathrm{W}$ & Q. robur & A. unedo, C. scoparius, Ulex europaeus, Q. robur \\
Born (Bo.) & Forest & $44^{\circ} 02^{\prime} \mathrm{N}, 1^{\circ} 17^{\prime} \mathrm{W}$ & $\mathrm{E}$ & Q. robur, Q. suber & Erica cinerea, U. europaeus, Q. robur \\
& Gap & $44^{\circ} 01^{\prime} \mathrm{N}, 1^{\circ} 17^{\prime} \mathrm{W}$ & $\mathrm{E}$ & Q. robur, Q. suber & C. scoparius \\
Seignosse (Se.) & Forest & $43^{\circ} 41^{\prime} \mathrm{N}, 1^{\circ} 25^{\prime} \mathrm{W}$ & $\mathrm{E}$ & Q. robur, Q. suber & A. unedo, I. aquifolium, $R$. aculeatus \\
& Gap & $43^{\circ} 41^{\prime} \mathrm{N}, 1^{\circ} 24^{\prime} \mathrm{W}$ & $\mathrm{E}$ & Q. robur, Q. suber & E. cinerea, Calluna vulgaris, $R$. aculeatus, Q. suber \\
\hline
\end{tabular}

Q. suber only occurred in southern plots) in this study for seedling-shrub spatial association analysis, we pooled the seedlings of the three oak species in one category. Moreover, since shrub functional groups are not constantly replicated in all site conditions and canopy conditions, the effects of canopy types and site conditions were also disregarded here. Thus, the main aim of this study was to assess the overall effect of different functional groups of shrubs, independently on canopy and climate conditions. We could not assess the interactions between the functional groups of shrubs, climate and canopy conditions with our spatial method because of lack of replication of each combination of these three treatments. For this main question, we used pair correlation function and chisquare (spatial and non-spatial methods, respectively).

\subsubsection{Univariate patterns}

To characterize the horizontal distribution of the seedlings of each oak species, we used the univariate pair correlation function adopting the null model of heterogeneous complete spatial randomness to ensure that the observed patterns were not forced by first-order effects (environmental heterogeneity) but rather by interaction between the points themselves (Wiegand and Moloney 2004).

$g 11(r)=E[\#$ (points of pattern 1 at a distance $r$ from an arbitrary point of the same points of pattern)]/ $\lambda 1$ is the univariate pair correlation function $g(r)$ which can be defined as the expected density of points of pattern 1 (oak seedlings) in a ring of radius $r$ and width $d w$ centred in an arbitrary point, divided by the intensity $(\lambda)(\lambda=\mathrm{n} 1 /$ area of plot $)$ of points of pattern 1 (Wiegand and Moloney 2004).

Values of $g(r)$ greater than equal to or lower than 1 indicate spatial aggregation, randomness or segregation distribution, respectively, at a given distance (Wiegand and Moloney 2004).

\subsubsection{Bivariate patterns}

To detect the association patterns between oak seedlings and the four functional groups of shrubs, we first used a widely common spatial point analysis function, pair correlation $g_{12}(r)$, with the $x, y$ coordinates of shrub crown centroids as input. Second, non-spatial analysis was used for testing the independency between the abundance of oak seedling individuals and estimated canopy surfaces of the different functional groups of shrubs (chi-square independence tests). The chi-square independence null model is non-spatial in the sense that it does not depend on the $x$ and $y$ coordinates of the plant. In other words, the presence of oak seedling depends only on the shrub canopy area (see Schleicher et al. 2011). This second method may help to overcome the spatial point pattern limitation where shrub canopies are reduced to point locations (Wiegand and Moloney 2004).

Pair correlation function (spatial method) To assess the influence of each functional group of shrubs on seedlings of oak species regeneration, we relocated shrub stems $x, y$ coordinates to the crown centroids expecting that interactions are more likely mediated by local light conditions beside the crown asymmetry among our studied shrubs (Umeki 1995). Spatial associations between crown centroid points and oak seedling stem locations were analysed using bivariate pair correlation functions. The pair correlation function is a noncumulative function where the spatial pattern at finer scales does not influence the function at broader scales, while Ripley's $k$-function detects association patterns cumulatively up to a certain distance $r$. The pair correlation function $g_{12}(r)$ is the analogue of Ripley's $k_{12}(r)$ when replacing the circles of radius $r$ by rings with radius $r . g_{12}(r)=E$ [\# (points of pattern 2 at a distance $r$ from an arbitrary point of pattern 1$)] / \lambda_{2}$, where $E$ [ ] is the expectation operator; pattern 2 and pattern 1 represent oak seedlings and shrubs, respectively; $\lambda_{2}$ (lambda 
2 ) is the intensity of pattern 2 and attraction and repulsion are evaluated through significance testing; $g_{12}(r)>1$ and $g_{12}(r)<1$ indicate attraction and repulsion between the two patterns at a distance $r$, respectively (Wiegand and Moloney 2004). For the used function, we compared the observed bivariate point patterns with the antecedent conditions null model, to test whether the pattern of oak seedlings was influenced by the pattern of shrubs during the establishment. For that purpose, the locations of the oak seedlings were randomized and shrub locations were maintained fixed (assuming that oak seedlings may occur anywhere in the plot and that the shrub pattern does not change during the development of seedlings; Wiegand and Moloney 2004). To detect the significance of patterns against the null models for both univariate and bivariate analyses, approximate (two-sided) $95 \%$ simulation envelopes of the null models were created by calculating for each distance $r$ the 5th lowest and highest values of the summary statistic from 99 Monte Carlo simulations of the null model; this yields an approximate $5 \%$ error rate. However, because of simultaneous inferences (i.e. we tested $r$ at several spatial scales simultaneously), type I error may occur if the value of the chosen statistic is close to a simulation envelope (i.e. the null model may be rejected even if true when values of the evaluated function are close to values of the simulation envelopes). We therefore combined the common simulation envelope method with a goodness-of-fit (GoF) test advocated by Loosmore and Ford (2006). In all analyses, we used a distance interval of $0.25 \mathrm{~m}$ with $0.5 \mathrm{~m} \mathrm{dr}$ (ring width) calculated up to 3 and $5 \mathrm{~m}$ for association and distribution patterns consequently. Point pattern analyses were performed using the software Programita (Wiegand and Moloney 2004, improved version of 2010).

Chi-square test (non-spatial method) A limitation of point pattern analysis is that plants are reduced to point locations. These point approximations are applicable when plant size is small in comparison to the investigated spatial scales. Consideration of real plant size and shape might therefore be especially important where the small-scale spatial structure of a plant community is concerned (Purves and Law 2002; Wiegand et al. 2006). Otherwise, it may obscure the real spatial relationships at smaller scales in which ecologists are particularly interested when they study interactions among plants (i.e. Prentice and Werger 1985). In order to overcome these limitations, we compared observed-to-expected oak seedling occurrence under the canopy of each shrub functional group using chi-square $\left(\chi^{2}\right)$ independence tests considering shrub canopy surfaces (i.e. canopy cover) rather than centroid point coordinates. The null hypothesis was that the presence of seedlings beneath the shrub canopies is independent of the functional group of shrubs (Schleicher et al. 2011). The seedlings beneath overlapping zones between shrub canopies of different groups were discharged from the analysis in order to avoid misinterpretation of results. The shrub canopy polygons were drawn in a computer-aided design (CAD) system (AutoCAD, Autodesk Inc., Sausalito, CA) by fitting bidimensional splines to the four coordinates endpoints recorded in the field. We exported the polygons to ArcGIS 10.1 (ESRI Inc., Redlands, CA), and the $x, y$ coordinates of polygon centroids were extracted (i.e. Fig. 1a-c). Chi-square analysis was performed using the R software for statistical computing (version 2.10.1, 2010).

\section{Results}

3.1 Univariate distribution patterns of the seedlings of each of the three oak species

A total of 4,963 oak seedlings belonging to three oak species were recorded and mapped, with an average of 451 seedlings per plot $\left(14,317\right.$ seedlings ha $\left.{ }^{-1}\right)(32,34$ and $34 \%$ for Q. robur, $Q$. ilex and $Q$. suber, respectively). By applying univariate pair correlation analysis, the significant $\mathrm{GoF}$ test values $(P<0.01)$ revealed generally similar aggregate patterns of regeneration for the three oak species at fine scale $<1 \mathrm{~m}$ (Fig. 2 and Appendix: Fig. S1 and Table S1) which confirms the visual inspection of the mapped patterns (Fig. 1a-c). Exceptions were recorded in Bo. and Bisc. $2 \mathrm{~F}$ sites where both $Q$. robur and $Q$. suber did not show significant nonrandom univariate patterns (Appendix: Fig. S1 and Table S1). Generally, the highest values of $g(r)$ occurred at short distances $(0.25$ to $1 \mathrm{~m})$ and faded away with increasing distance (Fig. 2 and Appendix: Fig. S1).

\subsection{Bivariate shrub-oak association patterns}

The total number of mapped shrub individuals was 1,217 with an average canopy area of $223 \mathrm{~cm}^{2}$. The GoF tests of the bivariate interspecific and intraspecific pair correlation function detected significant associations for 33 shrub-oak cases out of potential 43 tests ( 17 cases of positive and 16 cases of negative associations, Table 2 and Appendix: Table S2). Among the 16 Fagaceae shrub-oak seedling cases, there were $9(56.25 \%)$ positive, 4 negative $(25 \%)$ and 3 independent $(18.75 \%)$ interactions (Table 2). It is interesting to notice that the majority (i.e. 7) of these 9 positive association cases were intraspecific and only 2 were interspecific. Seedlings of oak species displayed significant negative spatial association with Ericaceae shrubs in 7 (58.33\%) out of 12 cases. Results of seven spatial association tests between spiny shrubs and oak seedling showed three cases of positive (42.86 \%) and three negative $(42.86 \%)(P=0.01)$ associations and one case of independence $(P=0.09)$. Out of eight cases, only three cases $(37.5 \%)$ of Fabaceae shrubs showed positive interactions with 

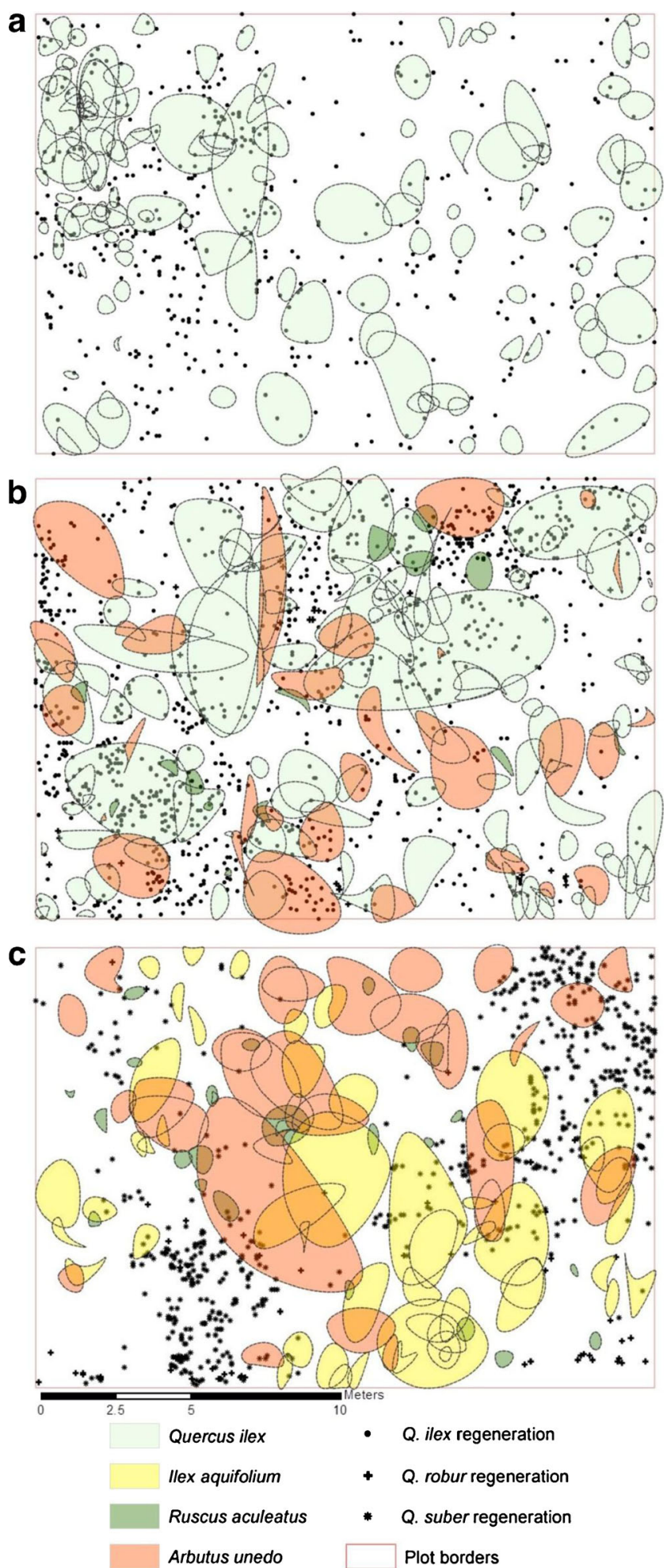

Fig. 1 Examples of plot $\left(315 \mathrm{~m}^{2}\right)$ maps showing crown projections of shrub canopy and location of oak regeneration. Spatial analyses performed in these plots revealed different overall spatial patterns between shrubs and regeneration, in particular a positive interaction (attraction) for Hourtin forest, b no interaction (independence) in Soulac forest and $\mathbf{c}$ negative interaction (repulsion) in Seignosse forest oak seedlings, and three cases (37.5\%) were independent in their interactions with two cases $(25 \%)$ of negative interactions (Table 2, Appendix: Table S2).

In short, bivariate analysis under the null model of antecedent condition (attraction/ repulsion) between shrubs and seedlings exhibited a higher density of oak seedlings neighbouring Fagaceae shrubs than the rest, as positive cases occurred more frequently with intraspecific Fagaceae $(56.25 \%)$. Negative interactions mainly occurred with Ericaceae shrubs (58.33\%), while $37.5 \%$ of Fabaceae interactions basically showed independence (Table 2 and Appendix: Table S2).

\subsection{Seedlings under shrub canopies}

Chi-square analyses showed that oak seedlings were significantly disassociated with the Ericaceae canopies in $50 \%$ of the cases whereas both positive and independent associations represented $25 \%$ of the patterns each (Table 2 and Fig. 3). Fagaceae shrubs showed attraction in seven cases among 16 $(43.75 \%)$, with six cases of intraspecific interaction. Repulsion was found with the same frequency (seven cases, $43.75 \%)$, but with more interspecific interactions $(25 \%)$, whereas there were only two independent patterns (12.5\%) (Table 2 and Fig. 3). From eight to seven association cases of Fabaceae and spiny, respectively, we did not find a strong tendency towards positive or negative association with an equal occurrence of the three association patterns (positive, negative and independent) (Table 2 and Fig. 3). In summary, chi-square analysis results were almost similar to those emerging from pair correlation function.

\section{Discussion}

Consistently with our expectations, we found that (1) seedlings of all three oak species were spatially aggregated at fine scales $(<1 \mathrm{~m})$ in most plots and (2) independent of species, oak seedlings had contrasting association patterns in relation to the four functional shrub groups. Association patterns were predominantly positive for Fagaceae, negative for Ericaceae, but more neutral for Fabaceae and spiny shrubs.

\subsection{Aggregated distribution of oak seedlings}

It is generally accepted that both random and regular distributions of tree regeneration tend to be an exception rather than a rule (Pardos et al. 2008). Tree seedlings are often aggregated at fine scales (e.g. $<1 \mathrm{~m}$, Salas et al. 2006). Among the 17 plot-species situations, we found in 9 (among 12) significant cases of aggregated univariate patterns that strong $g(r)$ values occurred mostly at short distances $(0.25-1 \mathrm{~m})$. Our findings are in line with results reported for seedlings of different oak species in natural stands, including $Q$. ilex and Quercus 

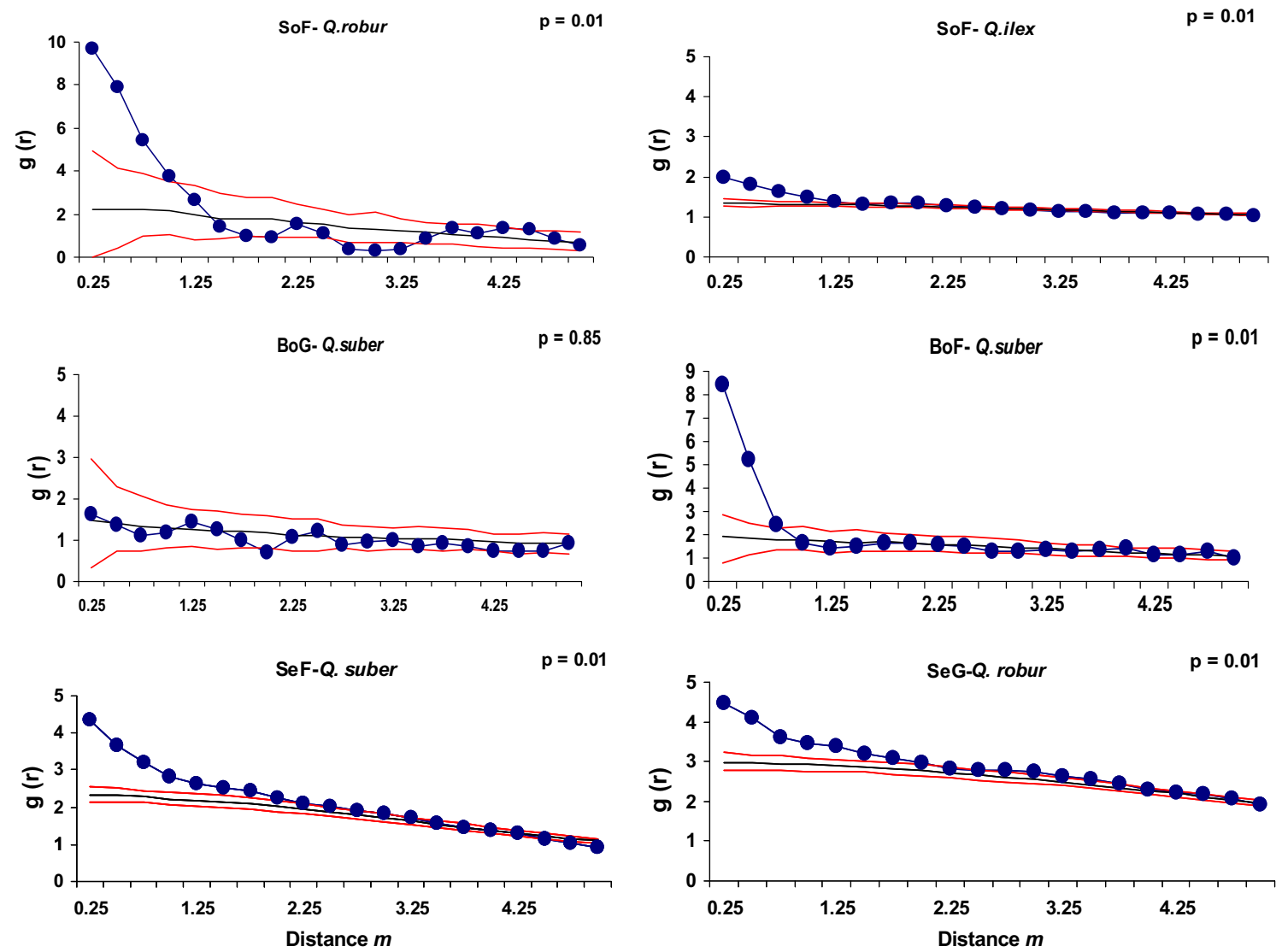

Fig. 2 Examples of univariate spatial distribution for the seedlings of the three oak species using pair correlation function. Lines with dots indicate ring statistics $g(r)$; red lines indicate the upper and lower limits of the $95 \%$ confidence envelope of the univariate heterogeneous spatial randomness null model. Points above, under and within envelopes indicate

aggregation, regular and random spatial distribution, respectively. The black solid line gives the expected $\mathrm{g}$ function value under the null model. See Table 1 for site abbreviations. Note that the $y$-axis scales are different

pubescens (McDonald et al. 2003) and Quercus faginea, Q. suber (Maltez-Mouro et al. 2007) and Q. robur (Andersson 1991). An aggregated pattern may be caused by limited seed dispersal distances (Kunstler et al. 2004), habitat heterogeneity (Harms et al. 2001), and overstory or understory

competition dynamics (Petritan et al. 2014) or a combination of these factors (Skarpe 1991). Hence, for Quercus, a genus characterized by large acorns typically distributed by gravity, short-distance seed dispersal could be a plausible reason for the observed aggregated patterns. However, facilitation could

Table 2 Association frequency and percentage of patterns of the seedlings of the three oak species with the four functional groups of shrubs in the eleven $315-\mathrm{m}^{2}$ plots derived from pair correlation function and chi-square analyses

The values in bold correspond to the highest values of association pattern recorded among the three types of associations (positive, negative and independent) for each of the four functional groups of shrubs. Fagaceae shrubs are sub-divided into intraspecific and interspecific association

\begin{tabular}{llllll}
\hline Analysis Method & Functional group & Positive & Negative & Independent & Total \\
\hline Pair correlation function & Fagaceae & $\mathbf{9 ( 5 6 . 2 5 )}$ & $4(25)$ & $3(18.75)$ & 16 \\
& Intraspecific & $\mathbf{7 ( 4 3 . 7 5 )}$ & $2(12.5)$ & $1(6.25)$ & 10 \\
& Interspecific & $2(12.5)$ & $2(12.5)$ & $2(12.5)$ & 6 \\
& Spiny & $3(42.86)$ & $3(42.86)$ & $1(14.29)$ & 7 \\
& Fabaceae & $3(37.5)$ & $2(25)$ & $3(37.5)$ & 8 \\
Ericaceae & $2(16.67)$ & $\mathbf{7 ( 5 8 . 3 3 )}$ & $3(25)$ & 12 \\
Chi-square & Fagaceae & $\mathbf{7 ( 4 3 . 7 5 )}$ & $7(43.75)$ & $2(12.5)$ & 16 \\
& Intraspecific & $\mathbf{( 6 ) ( 3 7 . 5 )}$ & $3(18.75)$ & $1(6.25)$ & 10 \\
& Interspecific & $1(6.25)$ & $4(25)$ & $1(6.25)$ & 6 \\
& Spiny & $2(28.57)$ & $3(42.86)$ & $2(28.57)$ & 7 \\
& Fabaceae & $3(37.5)$ & $2(25)$ & $3(37.5)$ & 8 \\
& Ericaceae & $3(25)$ & $\mathbf{6 ( 5 0 )}$ & $3(25)$ & 12 \\
\hline
\end{tabular}



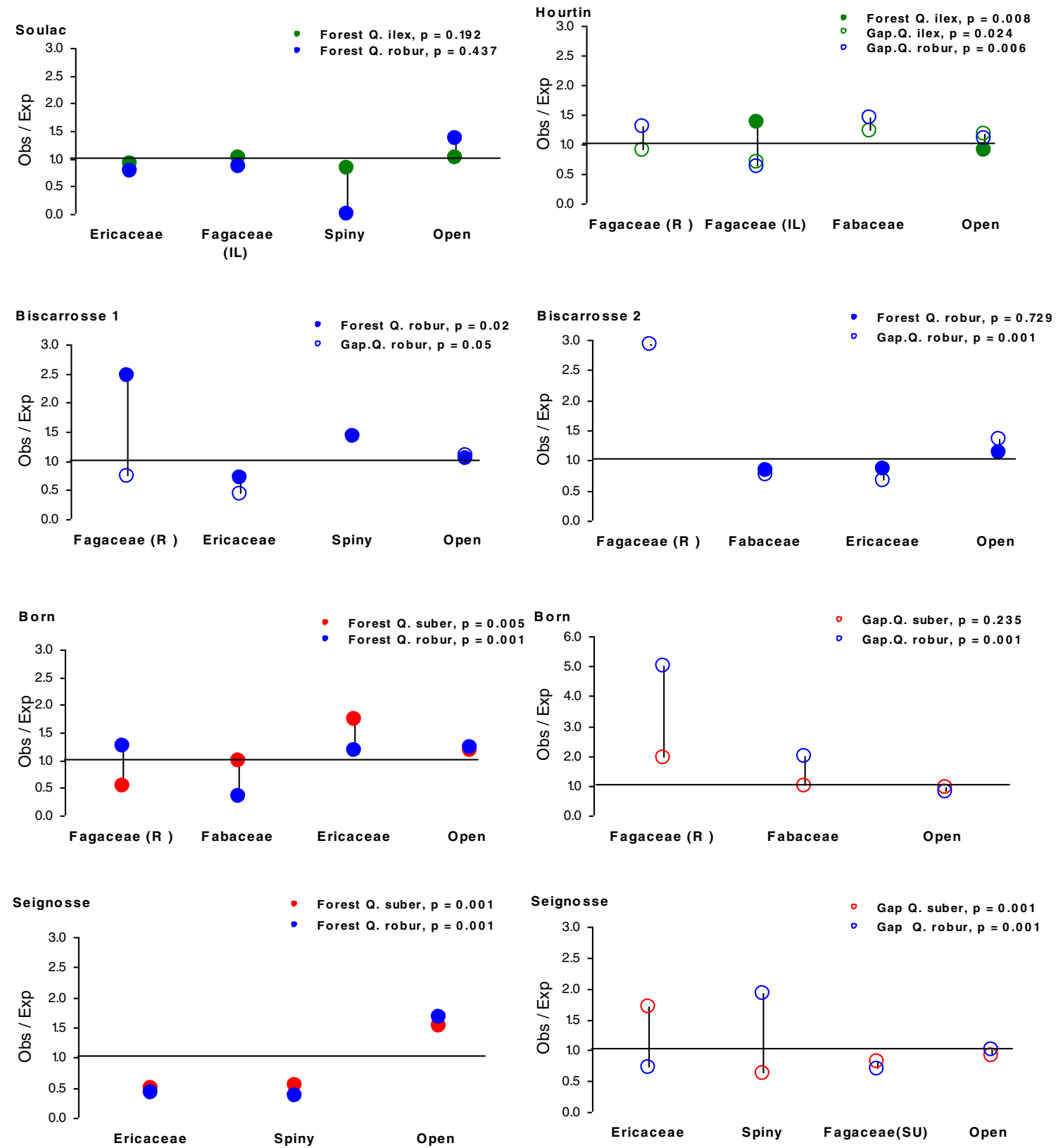

Fig. 3 Observed-to-expected frequency distribution of the three oak seedlings with different functional groups of shrub species and in different canopy and site conditions based on chi-square test. See Table 1 for site abbreviations

also in part explain such pattern of aggregation within the influence zone of particular shrubs, although intraspecific aggregation has also been shown to be due to reduced competition as compared to interspecific association (Stoll and Prati 2001). We did not find obvious differences in aggregation patterns among the three oak species. Indeed, the acorns of the three species have approximately the same size, and all three are dispersed primarily by gravity and secondarily by similar animal dispersal agents such as the Eurasian jay Garrulus glandarius (Gómez 2003). Additionally, aggregated seedlings have been shown to be potentially due to seed catching by small mammals (Schurr et al. 2004).

\subsection{Positive oak shrub-oak seedling association patterns}

The results of both methods used to quantify shrub-oak seedling association patterns showed that Fagaceae shrubs were overall spatially positively associated with oak seedlings and that most of these positive associations were intraspecific. Most studies conducted in xeric environmental conditions have considered that positive associations of tree seedlings with conspecific shrubs are evidence of facilitation (Tirado and Pugnaire 2003). However, under temperate oceanic climate conditions, this pattern needs to be interpreted with some caution since several other processes may drive such positive 
associations, including environmental heterogeneity (Michalet 2006) and seed dispersal distance (Schurr et al. 2005). Although we did not specifically document a withinsite environmental variation in our study, we assume that environmental heterogeneity was not the cause of these bivariate association patterns considering the relatively small size of our plots and their homogeneity in terms of topography, exposure and soil texture conditions. Rather, this positive association may have been caused by acorn dispersal and/or facilitation, e.g. improved conditions expected beneath host shrubs (Cuesta et al. 2010; Schleicher et al. 2011). As a rule, facilitation dominates when niche overlap is limited (interspecific) while competition for shared resources otherwise dominates (intraspecific). The stronger intraspecific than interspecific competition stressed by classic competition theory (Dullinger et al. 2007) has not always been supported by empirical work (Fajardo and McIntire 2011). Intraspecific facilitation may occur among individuals of the same species but from different life stages, with large individuals protecting small seedlings causing nurse effects to recruitment (Callaway 1995). This may partially explain our positive association pattern (naturally occurring oak seedlings around and beneath intraspecific Fagaceae shrubs). Additionally, Muhamed et al. (2013b) showed in a removal experiment in the same system that oak seedlings were facilitated by neighbours (including shrubs of different species), although this positive effect was only observed in the driest conditions (in the gaps of the North). In contrast in the current study, this positive pattern was observed across all sites, regardless of environmental stress due to climatic conditions, as is the case of the strong aggregation univariate patterns. Together, these arguments give more support to the limited acorn dispersal in the vicinity of adult trees as the likely dominant driver of these intraspecific positive associations between oak seedlings and Fagaceae shrubs. Although we are aware that shrubs do not produce acorns, both the shrubs and the oak seedlings may have recruited in the close neighbourhood of adult trees. Finally, both processes (barochory and facilitation) could potentially explain this pattern. For example, aggregated acorn dispersal from adult trees could be later enhanced by facilitation of seedlings by intraspecific shrubs. Since such processes are difficult to separate using an observational approach (Wiegand et al. 2007), removal experiments as well as seed dispersion studies should be encouraged in order to allow us to disentangle the respective roles of intraspecific facilitation and limited seed dispersal in our ecosystem.

4.3 Negative and independent shrub-oak seedling association patterns

The clear negative association between Ericaceae and oak seedlings was presumably due to the allelopathic leachate characteristic of this family (Ballester et al. 1982), particularly in the case of $C$. vulgaris, Erica vagans and A. unedo. Our results are in line with Gonzalez-Martinez and Bravo (2001) who found a negative correlation between Scots pine regeneration and a dense cover of Ericaceae shrubs (Daboecia cantabrica, E. cinerea, E. vagans and C. vulgaris) due to the inhibiting role of their aboveground parts and roots. Similar results were found by Eppard et al. (2005) where the litter and organic layer substrates of Ericaceae severely limited the regeneration of seedlings of $Q$. rubra, Tsuga canadensis and Pinus rigida. However, A. unedo was shown to have a facilitative effect on $Q$. ilex development, due to enhanced mycorrhisation (Richard et al. 2009). A too low replication of each species did not allow us to assess if these negative associations were evenly shared within our Ericaceae group or specific to some species.

The low number of positive associations for both Fabaceae and spiny shrubs in this study was somewhat unexpected because many studies have shown that both functional groups of shrubs have overall positive effects on other species, because of their direct enhancement of soil nutrients or indirect protection effect against herbivores, respectively (e.g. Callaway 1995). For spiny shrubs, this result may be due to the low overall herbivore pressure in this coastal dune system, while the low nutrient requirement of oak species may explain the lack of a positive association with Fabaceae shrubs. However, the low number of cases compared to the two other functional groups may also explain this neutral pattern observed in our study.

\section{Conclusion}

Our study provides further evidence for spatial aggregation of regeneration for three oak species in the coastal dune forests. This result, observed with the univariate analyses, as well as the significant positive intraspecific association pattern found between the seedlings of oak species and Fagaceae shrubs with the bivariate analyses, suggests the importance of limited seed dispersal for explaining spatial patterns of oak recruitment. However, further studies such as removal experiment are needed to really assess the contribution of intraspecific facilitation in shaping this pattern. We found that interactions between oak seedlings and shrubs were strongly dependent on the functional group of shrubs, as we observed frequent negative spatial associations between oak seedlings and Ericaceae species. We recommend that forest managers focus on the control of Ericaceae shrubs to enhance the regeneration of oak forests, while preserving the Fagaceae shrubs, at least as regeneration insurance.

Acknowledgments We are grateful to the "Office National des Forêts" (O.N.F.) for permission to work in coastal sand dune forests and, in particular, to Didier Canteloup for his advice during the site selection 
process. We thank Fabien Rizinjirabake and Chantal Hélou for assistance in the field and Fabio Meloni and Raffaella Marzano for CAD and GIS support. The first author received a scholarship from EU through Erasmus Mundus programme Lot 10.

\section{References}

Andersson C (1991) Distribution of seedlings and saplings of Quercus robur in a grazed deciduous forest. J Veg Sci 2:279-282

Ballester A, Vieitez AM, Vieitez E (1982) Allelopathic potential of Erica vagans, Calluna vulgaris, and Daboecia cantabrica. J Chem Ecol 8: 851-857

Callaway RM (1995) Positive interactions among plants. Bot Rev 61: 306-349

Cuesta B, Villar-Salvador P, Puertolas J, Benayas JMR, Michalet R (2010) Facilitation of Quercus ilex in Mediterranean shrubland is explained by both direct and indirect interactions mediated by herbs. J Ecol 98:687-696

Cushman JH, Waller JC, Hoak DR (2010) Shrubs as ecosystem engineers in a coastal dune: influences on plant populations, communities and ecosystems. J Veg Sci 21:821-831

David TS, Henriques MO, Kurz-Besson C, Nunes J, Valente F, Vaz M, Pereira JS, Siegwolf R, Chaves MM, Gazarini LC, David JS (2007) Water-use strategies in two co-occurring Mediterranean evergreen oaks: surviving the summer drought. Tree Physiol 27:793-803

Dullinger S, Kleinbauer I, Pauli H, Gottfried M, Brooker R, Nagy L, Theurillat JP, Holten JI, Abdaladze O, Benito JL, Borel JL, Coldea G, Ghosn D, Kanka R, Merzouki A, Klettner C, Moiseev P, Molau U, Reiter K, Rossi G, Stanisci A, Tomaselli M, Unterlugauer P, Vittoz P, Grabherr G (2007) Weak and variable relationships between environmental severity and small-scale co-occurrence in alpine plant communities. J Ecol 95:1284-1295

Eppard HR, Horton JL, Nilsen ET, Galusky P, Clinton BD (2005) Investigating the allelopathic potential of Kalmia latifolia L. (Ericaceae). Southeast Nat 4:383-392

Fajardo A, McIntire E (2011) Under strong niche overlap conspecifics do not compete but help each other to survive: facilitation at the intraspecific level. J Ecol 99:642-650

Forey E, Chapelet B, Vitasse Y, Tilquin M, Touzard B, Michalet R (2008) The relative importance of disturbance and environmental stress at local and regional scales in French coastal sand dunes. J Veg Sci 19: 493-502

Gómez JM (2003) Spatial patterns in long-distance dispersal of Quercus ilex acorns by jays in a heterogeneous landscape. Ecography 26 : 573-584

Gómez-Aparicio L, Zamora R, Hodar JA, Castro J, Baraza E (2004) Applying plant positive interactions to reforestation of Mediterranean mountains: a meta-analysis of the use of shrubs as nurse plants. Ecol Appl 14:1128-1138

Gonzalez-Martinez SC, Bravo F (2001) Density and population structure of the natural regeneration of Scots pine (Pinus sylvestris L.) in the High Ebro Basin (Northern Spain). Ann For Sci 58:277-288

Goreaud F, Courbaud B, Collinet F (1999) Spatial structure analysis applied to modeling of forest dynamics: a few examples. In: Amaro A, Tomé M (eds) Empirical and process based models for forest tree and stand growth simulation. Novas Tecnologias, Oeiras, pp 155-172

Harms KE, Condit R, Hubbell SP, Foster RB (2001) Habitat associations of trees and shrubs in a 50-ha neotropical forest plot. J Ecol 89:947959

Hille Ris Lambers J, Clark JS (2003) Effects of dispersal, shrubs, and density-dependent mortality on seed and seedling distributions in temperate forests. Can J For Res 33:783-795
Kunstler G, Curt T, Lepart J (2004) Spatial pattern of beech (Fagus sylvatica L.) and oak (Quercus pubescens Mill.) seedlings in natural pine (Pinus sylvestris L.) woodlands. Eur J For Res 123: $331-337$

Loosmore NB, Ford ED (2006) Statistical inference using the G or K point pattern spatial statistics. Ecology 87:1925-1931

Maltez-Mouro S, Garcia LV, Maranon T, Freitas H (2007) Recruitment patterns in a Mediterranean oak forest: a case study showing the importance of the spatial component. For Sci 53:645-652

Maun MA (1998) Adaptations of plants to burial in coastal sand dunes. Can J Bot 76:713-738

McDonald RI, Peet RK, Urban DL (2003) Spatial pattern of Quercus regeneration limitation and Acer rubrum invasion in a Piedmont forest. J Veg Sci 14:441-450

Michalet R (1991) Une approche synthétique bio pédoclimatique des montagnes méditerranéennes: exemple du Maroc septentrional. Thèse Université Joseph Fourier, Grenoble

Michalet R (2006) Is facilitation in arid environments the result of direct or complex interactions. New Phytol 169:3-6

Muhamed H, Maalouf JP, Michalet R (2013a) Summer drought and canopy opening increase the strength of the oak seedlings-shrub spatial association. Ann For Sci 70:345-355

Muhamed H, Touzard B, Le Bagousse-Pinguet Y, Michalet R (2013b) The role of biotic interactions for the early establishment of oak seedlings in coastal dune forest communities. For Ecol Manag 297: $67-74$

Paluch JG (2005) The influence of the spatial pattern of trees on forest floor vegetation and silver fir (Abies alba Mill.) regeneration in uneven-aged forests. For Ecol Manag 205:283-298

Pardos M, Montes F, Canellas I (2008) Spatial dynamics of natural regeneration in two differently managed Pinus sylvestris stands before and after silvicultural intervention using replicated spatial point patterns. For Sci 54:260-272

Petritan IC, Marzano R, Petritan AM, Lingua E (2014) Overstory succession in a mixed Quercus petraea-Fagus sylvatica old growth forest revealed through the spatial pattern of competition and mortality. For Ecol Manag 326:9-17

Prentice IC, Werger MJA (1985) Clump spacing in a desert dwarf shrub community. Vegetatio 63:133-139

Purves DW, Law R (2002) Fine-scale structure in a grass-land community: quantifying the plant's-eye view. J Ecol 90:121-129

Rameau JC, Mansion D, Dumé G (1993) Flore forestière française. Tome 2: montagnes. Institut pour le Développement Forestier, Paris

Rayburn AP, Schiffers K, Schupp EW (2011) Use of precise spatial data for describing spatial patterns and plant interactions in a diverse Great Basin shrub community. Plant Ecol 212:585-594

Richard F, Selosse MA, Gardes M (2009) Facilitated establishment of Quercus ilex in shrub-dominated communities within a Mediterranean ecosystem: do mycorrhizal partners matter? FEMS Microbiol Ecol 68:14-24

Rodriguez-Garcia E, Ordoñez C, Bravo F (2011) Effects of shrub and canopy cover on the relative growth rate of Pinus pinaster Ait. seedlings of different sizes. Ann For Sci 68:337-346

Salas C, Lemay V, Nunez P, Pacheco P, Espinosa A (2006) Spatial patterns in an old-growth Nothofagus obliqua forest in southcentral Chile. For Ecol Manag 231:38-46

Sardin T (2009) Guide des sylvicultures Forêts littorales atlantiques dunaires. ONF ed. p. 175

Schleicher J, Meyer KM, Wiegand K, Schurr FM, Ward D (2011) Disentangling facilitation and seed dispersal from environmental heterogeneity as mechanisms generating associations between savanna plants. J Veg Sci 22:1038-1048

Schurr FM, Bossdorf O, Milton SJ, Schumacher J (2004) Spatial pattern formation in semi-arid shrubland: a priori predicted versus observed pattern characteristics. Plant Ecol 173:271-282 
Schurr FM, Bond WJ, Midgley GF, Higgins SI (2005) A mechanistic model for secondary seed dispersal by wind and its experimental validation. J Ecol 93:1017-1028

Shumway SW (2000) Facilitative effects of a sand dune shrub on species growing beneath the shrub canopy. Oecologia 124:138-148

Skarpe C (1991) Spatial patterns and dynamics of woody vegetation in an arid savanna. J Veg Sci 2:565-572

Stoll P, Prati D (2001) Intraspecific aggregation alters competitive interactions in experimental plant communities. Ecology 82:319-327

Tirado R, Pugnaire FI (2003) Shrub spatial aggregation and consequences for reproductive success. Oecologia 136:296-301
Umeki K (1995) Importance of crown position and morphological plasticity in competitive interaction in a population of Xanthium canadense. Ann Bot 75:259-265

Wiegand T, Moloney KA (2004) Rings, circles, and null-models for point pattern analysis in ecology. Oikos 104:209-229

Wiegand T, Kissling WD, Cipriotti PA, Aguiar MR (2006) Extending point pattern analysis for objects of finite size and irregular shape. $\mathrm{J}$ Ecol 94:825-837

Wiegand T, Gunatilleke S, Gunatilleke N (2007) Species associations in a heterogeneous Sri Lankan dipterocarp forest. Am Nat 170: E77-E95 